\title{
Quality control index survey for railway bridge health monitoring
}

\author{
Sadegh Lajevardi \\ University of Minho, Guimarães, Portugal
}

Jose Matos

University of Minho, Guimarães, Portugal

\author{
Paulo B. Lourenço
}

University of Minho, Guimarães, Portugal

Contacting author: Sadegh.Lajevardi@gmail.com

\begin{abstract}
Inspection and rehabilitation are the most important activities during any maintenance procedure. A maintenance project demands to manage resources with regard to data related to components' condition, defined by a given index. In this manner, data sets obtained for each index, and for each case study, are used for finding the new quality control index with maximum value of data. In this approach, risk analysis is used for prioritization and reducing costs with increasing data value with focusing on important elements as well as maximizing value of information (Vol) in measurements and inspections. Risk analysis is the most common tool for data mining and intelligent judgment obtained from observations. Risk analysis results are usually calculated to find the weight for each data set index in terms of their scores, which are called factor scores and finding the new quality control indexed for each case.
\end{abstract}

Finally, the major and important index according to their weight and risk scores, is obtained and used for decision making in maintenance projects. An application is shown consisting of 29 Railway Bridges in suburban area with data obtained from periodic inspections. All of these bridges are constructed in reinforced concrete.

Finally, it is desirable to produce new check list with regard to important data and quality control indexes. The priority of each bridge in the railway network as well as the priority for each component in their structure could be obtained by the new quality control indexes. Resource planning usage for the network component could be determined by this approach after computation of the new quality control index. Resources planning consists of inspection intervals and their materials usage for maintenance activities.

Keywords: Project management; Risk Analysis; value of information; Railway Bridge; resource planning 


\section{Introduction}

Recently, several methods in structural health monitoring (e.g., image processing, speech processing, etc.) are common due to railway network expansion and data mining. With these methods, the volume of data increases when compared with data gathering which obtained by traditional methods. Mathematical methods and risk prioritization is important for reduction of data volume while keeping their value and reducing unimportant elements of structure and their dependent data. Raw data are usually not enough to provide safety during the operation of railway network [1].

The next step after gathering data is to develop a maintenance project plan as well as decision making according to structural condition rating. For this reason, safety prediction can be estimated by data which is gathered by structural health monitoring. Covering all equipment in railway networks require condition monitoring with automation systems applied for rapid wide railway network with agile decision making, combined with quality control [2]. According to recent description, inspectors are faced with many variables in quality control processes. In this manner, multivariate methods are helpful to analyze data with more than one random variable. There are a wide range of multivariate techniques available, as may be seen from the examples below:
$\checkmark$ Matrix plot
$\checkmark$ Correlation analysis
$\checkmark$ Radar spider
$\checkmark$ Principal component and factor analysis
$\checkmark$ Cluster analysis
$\checkmark$ Discriminant analysis
$\checkmark$ Neural network classifier
$\checkmark$ Partial least squares
$\checkmark$ Canonical correlation
$\checkmark$ Multivariate normality test
$\checkmark$ Multivariate tolerance limits
$\checkmark$ Multidimensional scaling

For maintenance decision making, it is necessary to find the priority task in each period and decide about the maintenance method. For this propose, research papers use many approached to calculate the operational reliability number, Risk Priority Number (RPN), failure occurrence, effect ranking and detection ranking in the case studies. A similar approach is use for finding defects in structural health monitoring. According to the International Union of Railways (UIC) handbook, railway tracks are faced with various types of failures. Generally, these defects can be grouped with three types as follows:

$\checkmark$ Geometry defect related to the railway track.

$\checkmark$ Physical defects are related with equipment and visible for inspectors.

$\checkmark$ Hidden irregularity, which is not visible for an inspector and is located in a component internal area.

According to a recent classification and risk assessment application, this paper investigates the integration between Structural Heath Monitoring (SHM) and Reliability Centered Maintenance (RCM). RCM is used for project management as an agile approach. Research survey was used for finding the integration between RCM, Maintenance method and project management in papers, as presented in table 1. Also, the survey strategy for each research method is presented in this table with regard to their data collection system. 
Table 1. Survey strategy and data analysis system in each research method

\begin{tabular}{|c|c|c|c|c|c|}
\hline No & $\begin{array}{l}\text { Publication } \\
\text { time and } \\
\text { reference } \\
\text { number }\end{array}$ & Field of study & $\begin{array}{l}\text { Including } \\
\text { software }\end{array}$ & $\begin{array}{l}\text { Using } \\
\text { prioritization } \\
\text { concept }\end{array}$ & Detail \\
\hline 8 & $\begin{array}{l}\text { Stare, } \\
(2014)[3]\end{array}$ & $\begin{array}{l}\text { Information } \\
\text { technology }\end{array}$ & & - & SPSS software \\
\hline 4 & $\begin{array}{l}\text { Binder, et al. } \\
(2014)[4]\end{array}$ & $\begin{array}{l}\text { Information } \\
\text { technology }\end{array}$ & - & - & $\begin{array}{l}\text { Agile project } \\
\text { management }\end{array}$ \\
\hline 7 & $\begin{array}{l}\text { Suprika, et al. } \\
(2015)[5]\end{array}$ & $\begin{array}{l}\text { Information } \\
\text { technology }\end{array}$ & - & - & - \\
\hline 6 & $\begin{array}{l}\text { Raja Mamat, } \\
\text { et al. } \\
(2016)[6]\end{array}$ & Carrier vehicle & $\nabla$ & - & $\begin{array}{l}\text { SmartPLS } \\
\text { software } \\
2.0 \\
\text { Key success } \\
\text { factors method }\end{array}$ \\
\hline 1 & $\begin{array}{l}\text { P Franková, } \\
\text { et al. } \\
(2016)[7]\end{array}$ & $\begin{array}{l}\text { Information } \\
\text { technology }\end{array}$ & - & $\nabla$ & $\begin{array}{l}\text { big data } \\
\text { management }\end{array}$ \\
\hline 2 & $\begin{array}{l}\text { M } \\
\text { Špundak[8] }\end{array}$ & $\begin{array}{l}\text { Management } \\
\text { study field }\end{array}$ & - & $\nabla$ & $\begin{array}{l}\text { Mixed } \\
\text { agile/traditional } \\
\text { project } \\
\text { management }\end{array}$ \\
\hline 3 & $\begin{array}{l}\text { A Rasnacis, et } \\
\text { al. (2017)[9] }\end{array}$ & $\begin{array}{l}\text { Management } \\
\text { study field }\end{array}$ & - & $\nabla$ & $\begin{array}{l}\text { Adaptation of } \\
\text { agile project } \\
\text { management }\end{array}$ \\
\hline 5 & $\begin{array}{l}\text { Oyebanji, et } \\
\text { al. (2017)[10] }\end{array}$ & $\begin{array}{l}\text { Building } \\
\text { construction }\end{array}$ & $\nabla$ & $\checkmark$ & $\begin{array}{l}\text { NVivo version } 10 \\
\text { software } \\
\text { Critical Success } \\
\text { Factor }\end{array}$ \\
\hline 13 & $\begin{array}{l}\text { H lei et al. } \\
(2017)[11]\end{array}$ & $\begin{array}{l}\text { Information } \\
\text { technology }\end{array}$ & $\nabla$ & $\nabla$ & $\begin{array}{l}\text { Scrum and } \\
\text { Kanban software }\end{array}$ \\
\hline
\end{tabular}


According to table 1 , research in many industrial fields focused on automation systems with agility approach on maintenance project planning. This paper, presents an approach for finding quality indexes according to monitoring data which are obtained from automation systems, with big data and decision making for maintenance. The main contribution of this paper is as follows:

I. Value of information (Vol)

a. Bridge condition

b. Recommended action

c. Cost estimation

II. Quality control index

III. Maintenance planning

This paper is structured as indicated next. Section 2 shows the application of Vol for finding quality control index raw data according to data obtained by a real case study. Section 3 presents an approach to reduce the volume of data gathered for future research. Section 4 describes the quality control index for maintenance planning in a real case study. These data are gathered from a suburban railway network which is located in Iran.

\section{Value of information}

Value of information ( $\mathrm{VOI}$ or $\mathrm{Vol}$ ) is the amount a decision maker would be willing to pay for information prior to making a decision (considering quality, risk or time).

\subsection{Value of information with considering time}

Value of information is defined in two periods of time, as follows.

\section{A. Before design}

B. During the operation with traditional design or preferred design

Many projects are faced with changes during the construction. Some of the projects suffered from insufficient preliminary studies and they experienced change during the operation. In all cases, engineers and decision makers have to evaluate the value of information which is related to the cost of design change. It is obvious that design changes during the operation are more costly than design changes before the operation. According to the Introduction, value of information could be estimated for each project in various type of subjects with regard to their timeline and the project condition.

\subsection{Value of information with quality consideration}

Preliminary studies and gathering information about the project and product will increase the quality. In a maintenance project, information would be defined by inspection and testing, also these data would be used for decision makers, which would increase the quality of structures during the operation. For this reason, quality index is the information which has to be supported by project budget to satisfy the safety during the operation period of time. Hence, it is necessary to optimize the information cost with regard to quality level. Thus, optimized value of information would be defined by risk analysis tools. A research study observed 29 bridges with visual inspection during the operation period over four years.

\subsection{Value of information with risk consideration}

If a designer predicts everything, the value of information increases and the cost associated with risk management would decrease. With this approach, it is necessary to find the optimum level of studies which would give information to designers and decision makers with acceptable risk. In this research, the value of information will be used for maintenance activities. Decision makers have to consider the value of information before the maintenance activities and decide about inspection costs. They have to reduce the risk level and find the optimum inspection and test costs which provide sufficient information regarding structures.

In this paper, a research approach finding the raw material data for quality control indexes according to this concept, realised by a risk factor as probability of failure and cost actions for each state.

\subsubsection{Bridge condition rate and probability of failure}

The first step for calculating the value of information, is to define each bridge condition. 
For this purpose, visual inspection check lists provide data from each component of bridges, chosen as case study as follows.

1. Super structure of Bridge

a. Track Superstructure
i. Switch
ii. Grease pump
iii. Ballast
iv. Rail
v. Joint
vi. Tie
vii. Fastening

b. Bridge deck
i. Barrier
ii. Beam
iii. Drainage

2. Substructure of bridge

a. Bridge pier
i. Elastomeric bearing support
ii. Pier cab

b. Abutments

3. Foundation of bridge
a. Pedestal
b. Footing

The checklists were completed during 4 years operation. There are 29 bridges made in reinforced concrete. Their average age is about 30 years.

Bridge state is defined by condition rating with regard to recent checklists. Failure in these checklists shows the potential damage according to standards. For example, many of the elements made by reinforced concrete exceed the maximum crack width according to the Eurocode standard and some other references in the same exposure condition, which is $0.3 \mathrm{~mm}[12,13]$.
The bridge state shows their condition rating in three status as follows.

i. Good status with grade 0

ii. Degraded with grade 1

iii. Poor with grade 2

Component's Failure of structure means exceeding over the limit state according standard. Component failure could be a reason for structural failure but it is not enough. According to last explanation, these grades are not subjective and they are related to number of failure of component or their defects observed in each visual test. These grades are comparative, based on failure or defects density. Failure density $\left(F_{d}\right)$ calculated with regard to total number of failures (F) divided by the approximate volume (V) of materials in each case, as given in formula 1 and 2.

$$
F_{d}=\frac{\Sigma F}{\int V d v}
$$

$$
V \simeq L \times W
$$

For each bridge (see table 2), $\mathrm{V}$ is an approximate measure representative of their volume with regard to length (L) and width (W). This shows that a larger bridge has more capacity for failure in it components when compared with a smaller one.

Failure densities $\left(F_{d}\right)$ are normalized by dividing them with the average of all failure densities. Meanwhile, there are many tools to normalize and this paper applied the following tools.
a) Normalization dimensionless method
b) Linear dimensionless method
c) Fuzzy dimensionless method 
Table 2. Bridge's components defect density and condition rate

\begin{tabular}{|c|c|c|c|c|c|c|}
\hline $\begin{array}{l}\text { Bridge } \\
\text { No }\end{array}$ & $\begin{array}{l}\text { Total number of } \\
\text { failure }\end{array}$ & $\begin{array}{c}\text { Approximate } \\
\text { volume of material }\end{array}$ & Failure density & $\begin{array}{l}\text { Normal failure } \\
\text { density }\end{array}$ & Threshold & $\begin{array}{c}\text { Condition } \\
\text { rate }\end{array}$ \\
\hline 1 & 7 & 941.42 & 0.007 & 0.015 & 0.034 & 0 \\
\hline 2 & 6 & 168.636 & 0.036 & 0.074 & 0.034 & 2 \\
\hline 3 & 4 & 142.584 & 0.028 & 0.058 & 0.034 & 1 \\
\hline 4 & 12 & 706.68 & 0.017 & 0.035 & 0.034 & 1 \\
\hline 5 & 4 & 141.96 & 0.028 & 0.058 & 0.034 & 1 \\
\hline 6 & 5 & 716.76 & 0.007 & 0.014 & 0.034 & 0 \\
\hline 7 & 4 & 142.428 & 0.028 & 0.058 & 0.034 & 1 \\
\hline 8 & 1 & 114.156 & 0.009 & 0.018 & 0.034 & 0 \\
\hline 9 & 4 & 507.11 & 0.008 & 0.016 & 0.034 & 0 \\
\hline 10 & 0 & 426.816 & 0.000 & 0.000 & 0.034 & 0 \\
\hline 11 & 7 & 142.272 & 0.049 & 0.102 & 0.034 & 2 \\
\hline 12 & 3 & 235.56 & 0.013 & 0.026 & 0.034 & 0 \\
\hline 13 & 4 & 429.624 & 0.009 & 0.019 & 0.034 & 0 \\
\hline 14 & 4 & 725.76 & 0.006 & 0.011 & 0.034 & 0 \\
\hline 15 & 8 & 360.048 & 0.022 & 0.046 & 0.034 & 1 \\
\hline 16 & 0 & 3260.4 & 0.000 & 0.000 & 0.034 & 0 \\
\hline 17 & 2 & 143.052 & 0.014 & 0.029 & 0.034 & 0 \\
\hline 18 & 8 & 714.4 & 0.011 & 0.023 & 0.034 & 0 \\
\hline 19 & 9 & 115.668 & 0.078 & 0.161 & 0.034 & 2 \\
\hline 20 & 9 & 1176.48 & 0.008 & 0.016 & 0.034 & 0 \\
\hline 21 & 0 & 162.792 & 0.000 & 0.000 & 0.034 & 0 \\
\hline 22 & 0 & 180.8 & 0.000 & 0.000 & 0.034 & 0 \\
\hline 23 & 1 & 169.2 & 0.006 & 0.012 & 0.034 & 0 \\
\hline 24 & 6 & 350.4 & 0.017 & 0.036 & 0.034 & 1 \\
\hline 25 & 19 & 4461.6 & 0.004 & 0.009 & 0.034 & 0 \\
\hline 26 & 2 & 460.2 & 0.004 & 0.009 & 0.034 & 0 \\
\hline 27 & 4 & 172.42 & 0.023 & 0.048 & 0.034 & 1 \\
\hline 28 & 5 & 169.832 & 0.029 & 0.061 & 0.034 & 1 \\
\hline 29 & 7 & 346.332 & 0.020 & 0.042 & 0.034 & 1 \\
\hline
\end{tabular}


According to formula 3 , defect density is calculated for each case.

$$
F_{d_{n}}=\frac{F_{d}}{\frac{\sum F_{d}}{n}}
$$

For finding the grade threshold between good, degraded and poor status, it is logical to divide the area under the normal distribution with three segments. In this way, there is a wide range of failure densities, located between 0 and 1 in $X$ axis and under the normal distribution on the $Y$ axis. So there are two thresholds and three segment to define three condition rates for each case study.

\subsubsection{Recommended action}

Repair actions, defined as follows for each bridge condition, are prescribed as a rough estimation (see Table 3).

i. Nothing to Do (ND) for good condition state

ii. $\quad$ Repair (R) for degraded condition rate

iii. Major Rehabilitation (MR) for poor condition rate

Table 3. Bridge's component defect density and condition rate

\begin{tabular}{|c|c|c|c|}
\hline $\boldsymbol{C}_{\boldsymbol{r}}$ & $\mathbf{0}$ & $\mathbf{1}$ & $\mathbf{2}$ \\
\hline Recommended action & $\mathrm{ND}$ & $\mathrm{R}$ & $\mathrm{MR}$ \\
\hline Total number $\boldsymbol{C}_{\boldsymbol{r}}$ & 17 & 9 & 3 \\
\hline Percentage (\%) & 58.6 & 31.0 & 10.3 \\
\hline
\end{tabular}

\subsubsection{Cost estimation}

There are 3 condition bridge states in observed cases as mentioned before, with the final condition for Bridge's components defect density that defines all type of cost maintenance. A fourth condition is assumed as bridge failure.

Cost of nothing to do, repair and major rehabilitation are obvious parameters. A last parameter $\left(\right.$ Cost $\left._{F}\right)$ is representative as a failure condition of bridge's component. In this bridge state, failure components would be completed and the bridge would become non-usable. In this research, there is no case with non-usable state, because all bridges were inspected during their operation.

These estimate costs are calculated by unit price of local reference and other references [14], with regard to currency change and labour cost as well as equipment and material approximate costs. The expected cost for each type of bridge in Iran is given in table 4.

Table 4. Expected cost for each bridge state

\begin{tabular}{|c|c|c|c|c|}
\hline Bridge state & $\mathbf{0}$ & $\mathbf{1}$ & $\mathbf{2}$ & $\mathbf{3}$ \\
\hline $\begin{array}{c}\text { Percentage of } \\
\text { frequency }\end{array}$ & 58.6 & 31.0 & 10.3 & 0 \\
\hline $\begin{array}{c}\text { Cost action (€) } \\
\text { Expected cost (€) }\end{array}$ & 0 & 12500 & 25000 & 125000 \\
\hline
\end{tabular}

\subsubsection{Quality control index}

If the change in bridge state is assumed with normal distribution, the probability of failure and their cost would be directly linked. In this approach it is possible to forecast the maintenance costs as quality control index for maintenance planning.

\section{Maintenance planning}

In this step, there are many methods available to choose for maintenance management. The expected cost is obtained using tools for decision making to define the maintenance method with optimized cost. For this purpose, alternatives would be various type of maintenance methods, as in table 5 , and decision criteria would be "expected cost, expected time and expected human resources, etc."

Table 5. Bridge's components defect density and their condition rate

Maintenance method

abbreviation 


\begin{tabular}{|c|c|}
\hline Preventive Maintenance & PM \\
\hline Predictive Maintenance & PM \\
\hline Productive Maintenance & PM \\
\hline Breakdown Maintenance & BM \\
\hline Corrective Maintenance & CM \\
\hline Emergency Maintenance & EM \\
\hline Maintenance Prevention & MP \\
\hline Condition Monitoring & CM \\
\hline Condition Based Maintenance & $\mathrm{CBM}$ \\
\hline Use Based Maintenance & UBM \\
\hline Time Based Maintenance & TBM \\
\hline Lean maintenance & - \\
\hline Agile Maintenance & - \\
\hline Virtual Maintenance & - \\
\hline Reliability Centered Maintenance & $\mathrm{RCM}$ \\
\hline Total Productive Maintenance & TPM \\
\hline
\end{tabular}

Expected cost is investigated in this paper for 29 bridges and it is possible to forecast the expected cost for each case over time, as mentioned before. So, it is necessary to change the maintenance method according to the bridge state in each period of time. Also, it is important to consider other resources such as time and human in decision making for finding the best maintenance planning.

\section{Conclusions}

This paper introduced briefly a technique for finding the defect density with a risk based value of information to assist maintenance managers to decide about their activities during the operation. These tools were applied for a real case study to customize checklist and finding important inspection method according to condition for each bridge in a railway network. The case study located in Iran, with 29 bridges which made by reinforced concrete but the method could be exploited for any condition and bridge. In a first step, value of information was calculated by bridge states according to real observation over 4 years and the bridge states were shown predictable over the time with normal distribution. In each case, the expected resources (e.g., cost, time and etc.) are determined to define decision making criteria and maintenance method.

This paper presents the value of information and expected cost, to show the optimum maintenance plan according to a decision making based on these data. There are diverse decision making techniques which work with the data. For finding a dynamic maintenance plan over the time, it is useful to update bridge state and condition. If the visual inspection is not updated over time, and condition monitoring is poor, this system will not work well. On the other hand, this decision making system is necessary for Railway Bridge infrastructure, due to their repetitive load and changes.

For future research, the decision making systems briefly introduced will be considered. Also, finding multivariate techniques for reducing data volume will be proposed for improve quality control index and future research works.

\section{References}

[1] Hanley, C., Matos, J. C., Kelliher, D., \& Pakrashi, V. (2017). Integrating multivariate techniques in bridge management systems. Journal of Structural Integrity and Maintenance, 5314(November), 143-151. https://doi.org/10.1080/24705314.2017.1 354280

[2] Zhang, Y., Han, J., Liu, J., Zhou, T., Sun, J., \& Luo, J. (2017). Safety Prediction of Rail 
Transit System Based on Deep Learning, 851-856.

[3] Stare, A. (2014). Agile project management in product development projects. Procedia - Social and Behavioral Sciences, $\quad$ 119, 295-304. https://doi.org/10.1016/j.sbspro.2014.03. 034

[4] Binder, J., Aillaud, L. I., \& Schilli, L. (2014). The Project Management Cocktail Model: An Approach for Balancing Agile and ISO 21500. Procedia - Social and Behavioral Sciences, 119(119), 182-191. https://doi.org/10.1016/j.sbspro.2014.03. 022

[5] Suprika, V. Shrivastava, S. V., \& Rathod, U. (2015). Categorization of risk factors for distributed agile projects. Information and Software Technology, 58, 373-387. https://doi.org/10.1016/j.infsof.2014.07.0 07

[6] Raja Mamat, T. N. A., Mat Saman, M. Z., Sharif, S., \& Simic, V. (2016). Key success factors in establishing end-of-life vehicle management system: A primer for Malaysia. Journal of Cleaner Production, 135, 1289-1297. https://doi.org/10.1016/j.jclepro.2016.06. 183

[7] Frankova, P., Drahosova, M., \& Balco, P. (2016). Agile Project Management Approach and its Use in Big Data Management. Procedia Computer Science, 83(Ant), 576-583. http://doi.org/10.1016/j.procs.2016.04.27 2

[8] Špundak, M. (2014). Mixed Agile/Traditional Project Management Methodology - Reality or Illusion? Procedia - Social and Behavioral Sciences, 119, 939-948. http://doi.org/10.1016/j.sbspro.2014.03.1 05

[9] Rasnacis, A., \& Berzisa, S. (2016). Method for Adaptation and Implementation of Agile Project Management Methodology. Procedia Computer Science, 104(December 2016), 43-50. http://doi.org/10.1016/j.procs.2017.01.05 5
[10]Oyebanji, A. O., Liyanage, C., \& Akintoye, A. (2017). Critical Success Factors (CSFs) for achieving sustainable social housing (SSH). International Journal of Sustainable Built Environment. https://doi.org/10.1016/j.ijsbe.2017.03.00 6

[11]H lei, F, Ganjizadeh (2015). A statistical analysis of the effects of Scrum and Kanban on software development. Robotic and computer, 61, 124-144.

[12] Eurocode(Cl 7.3.3), GuideEC2 - Version V7, APPLICATION TO CONCRETE HIGHWAY BRIDGES, (2017) Table 10.2

[13]American Concrete Institute, ACl 224R-01, Control of Cracking in Concrete Structures, (2001). Table 4.1

[14]Design, L., Quirk, L., Matos, J., Murphy, J., \& Pakrashi, V. (2017). Visual inspection and bridge management. Structure and Infrastructure Engineering, 2479(July), 113.

https://doi.org/10.1080/15732479.2017.1 $\underline{352000}$

[15]Hanley, C., Matos, J. C., Kelliher, D., \& Pakrashi, V. (2017). Integrating multivariate techniques in bridge management systems. Journal of Structural Integrity and Maintenance, 5314(November), 143-151. https://doi.org/10.1080/24705314.2017.1 $\underline{354280}$ 